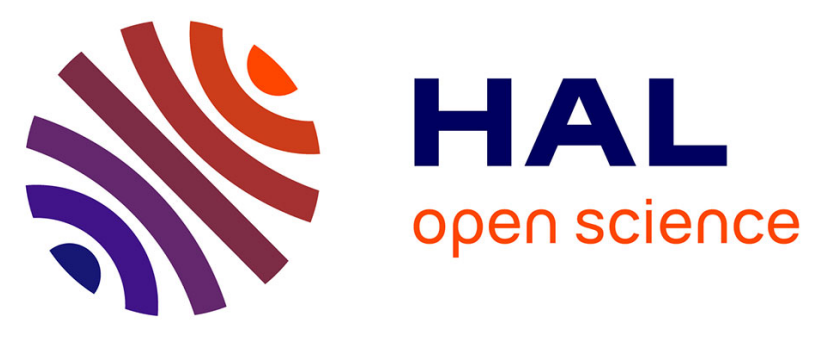

\title{
Impact of Polar Renal Artery Coverage after Fenestrated Endovascular Aortic Repair for Juxtarenal and Type IV Thoracoabdominal Aortic Aneurysms
}

Fabien Lareyre, Juliette Raffort, Joseph Carboni, Julien Chikande, Nicolas

Massiot, Audrey Voury-Pons, Emilien Umbdenstock, Réda Hassen-Khodja, Elixène Jean-Baptiste

\section{To cite this version:}

Fabien Lareyre, Juliette Raffort, Joseph Carboni, Julien Chikande, Nicolas Massiot, et al.. Impact of Polar Renal Artery Coverage after Fenestrated Endovascular Aortic Repair for Juxtarenal and Type IV Thoracoabdominal Aortic Aneurysms. Annals of Vascular Surgery, 2019, 58, pp.45 - 53.e1. 10.1016/j.avsg.2018.10.040 . hal-03486111

\section{HAL Id: hal-03486111 \\ https://hal.science/hal-03486111}

Submitted on 20 Dec 2021

HAL is a multi-disciplinary open access archive for the deposit and dissemination of scientific research documents, whether they are published or not. The documents may come from teaching and research institutions in France or abroad, or from public or private research centers.
L'archive ouverte pluridisciplinaire HAL, est destinée au dépôt et à la diffusion de documents scientifiques de niveau recherche, publiés ou non, émanant des établissements d'enseignement et de recherche français ou étrangers, des laboratoires publics ou privés.

\section{(ㅇ)(1) $\$$}

Distributed under a Creative Commons Attribution - NonCommerciall 4.0 International 
1

2

3

4

5 Fabien Lareyre ${ }^{1,2}$, Juliette Raffort ${ }^{2,3}$, Joseph Carboni ${ }^{1}$, Julien Chikande ${ }^{1}$, Nicolas Massiot ${ }^{1}$, 6

\section{7}

8

9 aneurysm, thoraco-abdominal aneurysm

\section{Impact of polar renal artery coverage following fenestrated endovascular aortic repair} (FEVAR) for juxta-renal and type IV thoraco-abdominal aortic aneurysms
Audrey Voury-Pons ${ }^{1}$, Emilien Umbdenstock ${ }^{1}$, Réda Hassen-Khodja ${ }^{1,2}$, Elixène Jean-

Baptiste $^{1,2}$

(1) Department of Vascular Surgery, University Hospital of Nice, France

(2) Université Côte d'Azur, CHU, Inserm, C3M, Nice, France

(3) Clinical Chemistry Laboratory, University Hospital of Nice, France

Correspondence to be addressed to:

Fabien Lareyre, MD,

Department of Vascular Surgery, University Hospital of Nice, France

30 Avenue de la Voie Romaine, 06001 Nice, France

Fax: +33 (0)4 92033839

Telephone number: +33 (0)4 92032941

Email address: fabien.lareyre@gmail.com

Category of manuscript: Original article

Short title: Consequences of polar coverage during FEVAR 


\section{Abstract}

Introduction: Fenestrated endovascular aortic repair (FEVAR) of complex aneurysm can require the coverage of polar renal artery. The aim of this study was to investigate the impact of the procedure on post-operative outcomes in patients with juxta-renal or thoraco-abdominal aortic aneurysms.

Material and methods: Patients who had FEVAR for juxta-renal or type IV thoracoabdominal aortic aneurysm were retrospectively included between January 2010 and October 2017. The estimated glomerular filtration rate (eGFR) was recorded before and at 1,7-day post-surgery and at the last follow-up. The occurrence of renal infarct was analyzed on the injected CT-scan images.

Results: Forty-three patients deemed at high-risk for open repair underwent FEVAR; 10 patients $(23.3 \%)$ had polar renal artery coverage and were compared to patients without polar renal artery. The eGFR did not differ between the groups at 1 and 7 days following FEVAR (respectively 69 vs $61.6 \mathrm{~mL} / \mathrm{mn} / 1.73 \mathrm{~m}^{2}, \mathrm{p}=0.8708$ and $68.4 \mathrm{~mL} / \mathrm{mn} / 1.73 \mathrm{~m}^{2}$ vs $68, \mathrm{p}=0.9440$ ). For a median follow-up of 233 days, the eGFR at the latest follow-up was $38 \mathrm{~mL} / \mathrm{mn} / 1.73 \mathrm{~m}^{2}$ $(21.8-56.3)$ in patients who had polar renal artery covered and $57 \mathrm{~mL} / \mathrm{mn} / 1.73 \mathrm{~m}^{2}(46.5-76)$ in patients without polar renal artery $(\mathrm{P}=0.0748)$. Patients who had polar renal artery had a higher rate of post-operative kidney renal infarct ( $60 \%$ vs $21.2 \%, \mathrm{p}=0.0441)$. The proportion of vascular complications did not differ ( $30 \%$ vs $30.3 \%, \mathrm{p}=0.9999)$. No endoleak related to polar renal artery coverage was observed. The 30-day post-operative mortality was $4.7 \%$. Conclusion: Polar renal artery coverage during FEVAR is not associated with critical renal and vascular short-term outcomes but could impact long-term renal function. 


\section{Introduction}

55 Since its development, endovascular aneurysm repair (EVAR) has rapidly evolved and has become an alternative therapeutic option to open surgery in patients with aortic aneurysm (1)

(2). The development of new devices has allowed to propose EVAR in patients with challenging anatomy including hostile neck, difficult vascular access or inclusion of visceral arteries (3-6). When the aneurysm is located above the renal arteries, the endovascular treatment requires to incorporate the visceral vessels to avoid ischemia and this can be achieved using fenestrated endografts (3). However, even if fenestrated endografts spare the main visceral vessels such as the mesenteric, renal and celiac arteries, their placement leads to the coverage of other collateral arteries. The vascular anatomy of the kidney region can differ among individuals (7) and the presence of a polar renal artery represents a frequent anatomic variation which can be observed between 12 and $25 \%$ of the population (7-9). When the aneurysm is juxta-renal or thoraco-abdominal, the presence of a polar renal artery may require its coverage by the fenestrated endograft. The impact of polar renal artery coverage during fenestrated endovascular aneurysm repair (FEVAR) has been so far poorly investigated. In this context, the aim of this study was to investigate the impact of polar renal artery coverage during FEVAR on early post-operative outcome.

\section{Material and methods}

\section{Population}

A retrospective study was performed in the Department of Vascular Surgery at the University Hospital of Nice. The study was registered with the authorization number E.H.V./C.G/2018/095 287 - 288. Consecutive patients deemed at high risk for open repair 

obstruction (13).

and who had a fenestrated endovascular aortic repair (FEVAR) for juxta-renal or type IV thoraco-abdominal aortic aneurysms were included from January 2010 to October 2017. Type IV thoraco-abdominal aortic aneurysms were defined according to Crawford classification (10). The indication of FEVAR was evaluated by a pluridisciplinary team composed of vascular surgeon and anesthetist based on clinical and anatomical characteristics of patients, according to current guidelines $(11,12)$. The surgical risk was evaluated by a multidisciplinary team including vascular surgeons and anesthetists. Zenith fenestrated aortic endografts (Cook Medical®, Bloomington, Ind) were used for all patients. The surgical procedure was performed by the same team composed of two trained operators in a nonhybrid operating room. The sizing of the stent grafts was performed by an experienced vascular surgeon with subsequent agreement with the manufacturer who reviewed the graft plan in every case. Clinical pre-operative characteristics were collected and included age, body mass index, the presence of cardiovascular risk factors, cardiac, pulmonary and renal comorbidities as well as the American Society of Anesthesiologists (ASA) score. Preoperative treatment was collected and change of medical treatment after the intervention was defined as the adjunction or the withdrawal at the time of discharge of at least one drug including angiotensin II converting enzyme inhibitor, beta-blocker, angiotensin II receptor blocker, calcium channel blockers, diuretics, antiplatelet therapy, oral anti-diabetic, anticoagulant or statin. Aneurysm characteristics and the anatomy of polar renal arteries were characterized on the pre-operative CT-scan by two independent operators. The technical success of the intervention was defined according to the Society for Vascular Surgery guidelines and corresponded to the successful introduction and deployment of the device, in the absence of surgical conversion to open repair, death at $24 \mathrm{~h}$, type I or III endoleak, or graft 
105 Renal function was evaluated based on the serum creatinine concentrations and the estimated 106 glomerular filtration rate (eGFR) was calculated according to the Chronic Kidney Disease 107 EPIdemiology collaboration (CKD-EPI) equation (14). Chronic renal failure was defined as 108 eGFR inferior to $60 \mathrm{~mL} / \mathrm{mn} / 1.73 \mathrm{~m}^{2}$ according to the chronic kidney disease staging system 109 developed by the National Kidney Foundation and was graded as followed: grade 3A for an 110 eGFR between 45 and $59 \mathrm{~mL} / \mathrm{mn} / 1.73 \mathrm{~m}^{2}$; grade 3B for an eGFR between 30 and 44 $111 \mathrm{~mL} / \mathrm{mn} / 1.73 \mathrm{~m}^{2}$; grade 4 for an eGFR between 15 and $29 \mathrm{~mL} / \mathrm{mn} / 1.73 \mathrm{~m}^{2}$ and grade 5 for an 112 eGFR inferior to $15 \mathrm{~mL} / \mathrm{mn} / 1.73 \mathrm{~m}^{2}$.

113 The changes of eGFR over time were evaluated for each patient and compared to the pre114 operative value. Renal deterioration was defined as a decrease of eGFR more than $25 \%$ 115 compared to baseline in accordance with the RIFLE system (15).

116 The presence of a renal infarct and the patency of the renal arteries was evaluated on the post117 operative injected CT-scan by a radiologist and a vascular surgeon. Injected CT-scan required 118 a volume of contrast agent of $90 \mathrm{~mL}$ and was performed the days following the surgery.

119 Vascular complications were defined as any endoleak, stent or graft occlusion, limb or 120 visceral ischemia, dissection or rupture and major bleeding (bleeding associated with a drop 121 in the hemoglobin of at least $3 \mathrm{~g} / \mathrm{dL}$ or requiring transfusion of 2 or more whole blood/ red 122 blood cells or causing a permanent injury or requiring surgery). The patency of the stented 123 vessels was evaluated on post-operative CT-scan.

\section{Data collection}

126 Data were collected using electronic and manuscript medical records, as well as the so-called

127 Clinicom ${ }^{\circledR}$ computer software program. Imaging data were collected from the software called 128 picture archiving and communication system (PACS-Carestream®). 
130

131 To evaluate the early impact of polar renal artery coverage after FEVAR, patients who had polar renal artery coverage were compared to those who did not have polar renal artery. The

13 study endpoints were the early post-operative renal and vascular outcomes as well as the 30-

\section{Statistical analysis}

137 Categorical data were expressed as the number of patients and percentage and continuous 138 GraphPad Prism® software (version 7.00, La Jolla California USA).

142

\section{Results}

\section{Study population and baseline data}

145 In total, 51 patients deemed at high-risk for open repair underwent fenestrated endograft

146 during the study period (Figure 1). Were included in the current analysis, 43 patients (Table

147 1) who underwent FEVAR for a juxta-renal AAA in 35 cases $(81.4 \% \%)$ or for a type IV

148 thoraco-abdominal aneurysm in 8 cases (18.6\%). Eight patients with type II, III or type I

149 thoraco-abdominal aneurysms were excluded. The median age of the cohort was 76 years

150 (interquartile range: $69-83$ ) and $95.4 \%$ were men. The body mass index was $23.9 \mathrm{~kg} / \mathrm{m}^{2}$

151 (21.3 - 27.4). The left ventricle ejection fraction was $60 \%(50-67.3)$. Twenty-four patients

$152(55.8 \%)$ had a coronary artery disease, $8(18.6 \%)$ a history of stroke, $9(20.3 \%)$ a chronic

153 obstructive pulmonary disease and $11(25.6 \%)$ a pre-operative chronic renal failure. Among 
154 patients with pre-operative renal failure, 7 patients were graded as $3 \mathrm{~A}, 3$ patients as $3 \mathrm{~B}$ and 1

155 patient as grade 4. The median ASA score was $3(3-3)$.

156

157

Intraoperative data

158 Thirteen patients (30.2\%) had a 2-fenestrations stent graft, $18(41.9 \%)$ a 3 -fenestrations graft 159 and $12(27.9 \%)$ had a 4-fenestrations graft. Stented vessels concerned the right renal artery in 16040 patients (93\%), the left renal artery in 40 (93\%), the superior mesenteric artery in 32

161 (74.4\%) and the celiac trunk in 16 patients (37.2\%). Of note, 3 patients did not have a stent in 162 both renal arteries as they had only one kidney. Vessel cannulation was successfully achieved 163 in all patients for all target arteries. The intervention was successful in all patients, but one 164 patient experienced a distal type I endoleak due to malposition of the right iliac limb. This last 165 patient was endo-converted to an aorto-uni-iliac configuration and crossover femoral-femoral bypass at the $7^{\text {th }}$ post-operative day.

167 The presence of a polar renal artery was observed in 10 patients (23.3\%). Among them, 8 168 patients had a unique polar renal artery and 2 patients had 2 polar renal arteries. The mean 169 diameter of the polar renal artery was $3.4 \mathrm{~mm}(3-4)$. The polar renal artery originated from 170 the aorta for 8 patients $(80 \%)$ and from the renal artery for 2 patients $(20 \%)$. All of them were 171 covered during the procedure. It was directed toward the superior pole, the inferior pole or the 172 hilum of the kidney in respectively 3 cases (30\%), 6 cases $(60 \%)$ or 1 case (10\%).

174 Early post-operative period

175 Patients who had a polar renal artery covered were compared to those without polar renal 176 arteries (Table 2). Clinical characteristics including age, history of cardiovascular risk factors 177 and comorbidities did not differ among the groups. The proportion of juxta-renal and type IV 178 thoraco-abdominal aneurysms did not differ between the 2 groups (respectively $80 \%$ vs. 
$81.8 \%, \mathrm{p}=0.9999$ and $20 \%$ vs $18.2 \%, \mathrm{p}=0.9999)$. The procedural characteristics were also comparable, with no significant difference on the proportion of the different types of fenestrated stent graft and stented vessels. The operative time did not differ between the 2 groups (respectively 240 vs $300 \mathrm{~min}, \mathrm{p}=0.4630$ ), neither the volume of contrast agent used (197 mL vs $135, \mathrm{p}=0.2107)$.

The renal function was evaluated and the proportion of pre-operative chronic renal failure did not significantly differ: 1 patient $(10 \%)$ vs 10 patients $(30.3 \%), \mathrm{p}=0.4086$. The pre-operative eGFR did not differ among the groups $\left(77.7 \mathrm{~mL} / \mathrm{mn} / 1.73 \mathrm{~m}^{2}\right.$ vs $\left.71.6, \mathrm{p}=0.4738\right)$ and no significant differences were observed at 1 and 7 days following the intervention (respectively 69 vs $61.6 \mathrm{~mL} / \mathrm{mn} / 1.73 \mathrm{~m}^{2}, \mathrm{p}=0.8708$ and $68.4 \mathrm{~mL} / \mathrm{mn} / 1.73 \mathrm{~m}^{2}$ vs $68, \mathrm{p}=0.9440$ ). In patients who had polar renal arteries covered, even if the eGFR tended to decrease at 1 and 7 day-postsurgery compared to pre-operative values, the difference did not reach statistical significance (68.9 and 68.4 vs $77.7 \mathrm{~mL} / \mathrm{mn} / 1.73 \mathrm{~m}^{2}$ pre-operatively, $\mathrm{p}=0.3926$ ).

\section{Follow-up}

The creatinine concentration and the eGFR obtained at the last follow-up were evaluated. The median follow-up was 233 days $(14.3-1147.3)$. The creatinine concentration at the last follow-up was $159 \mu \mathrm{mol} / \mathrm{L}(111.8$ - 253.3) in patients who had a polar renal artery covered and $102.5 \mu \mathrm{mol} / \mathrm{L}(81.3-126)$ in patients without a polar renal artery $(\mathrm{P}=0.0572)$. The eGFR was respectively $38 \mathrm{~mL} / \mathrm{mn} / 1.73 \mathrm{~m}^{2}(21.8-56.3)$ and $57 \mathrm{~mL} / \mathrm{mn} / 1.73 \mathrm{~m}^{2}(46.5-76)$, $\mathrm{P}=0.0748$. The proportion of patients who had a post-operative decrease of eGFR $(>25 \%$ compared to baseline) was respectively 4 patients (40\%) and 7 patients $(21.2 \%), \mathrm{P}=0.2477$. As the presence of a pre-operative chronic renal failure can potentially impact on the results, we analyzed the changes of renal function in these patients. Compared to pre-operative 
values, patients with chronic renal failure did not have a higher risk to have a post-operative decrease of eGFR at 1, 7 days and at the last follow-up (Supplemental Table).

Patients who had polar renal artery coverage had significantly a higher proportion of postoperative kidney renal infarct compared to those without polar renal artery (60\% vs $21.2 \%$, $\mathrm{p}=0.0441$ ). In patients who had a polar renal artery coverage, the renal infarct occurred in the territory of the covered vessel. In patients who did not have a polar renal artery, renal infarct was due to an occlusion of the renal stent for one patient, and to embolism or dissection of the renal parenchymal arteries for the other 6 patients. In patients who had polar renal artery coverage, the eGFR at the last follow-up post-intervention did not significantly differ between patients who developed a kidney renal infarct post-operatively and those who did not $(69.5$ $\mathrm{mL} / \mathrm{mn} / 1.73 \mathrm{~m}^{2}$ vs $70.6, \mathrm{p}=0.9999$ and $64.7 \mathrm{~mL} / \mathrm{mn} / 1.73 \mathrm{~m}^{2}$ vs $\left.68.4, \mathrm{p}=0.9048\right)$. The diameter of the polar renal artery did not differ between patients who developed a renal infarct and those who did not (3.1 $\mathrm{mm}$ vs 3.8, $\mathrm{p}=0.3810)$.

The 30-day post-operative mortality in the all cohort was $4.7 \%$ (2 patients) and was observed in patients who had polar renal artery covered $(\mathrm{P}=0.0498)$. The causes of the death were a multi-organ deficiency for the first patient and spinal cord ischemia for the second patient. The proportion of vascular complications did not differ between patients who had polar renal artery covered and those who did not ( $30 \%$ vs $30.3 \%, \mathrm{p}=0.9999)$. The presence of type II endoleak was checked on the post-operative CT-scan. The median time when the CT-scan was performed was 5 days $(2.8-7)$ after the surgery. Type II endoleaks were observed in 1 patient (10\%) in the group with polar renal artery coverage and 3 patients $(9.1 \%)$ without polar renal artery $(\mathrm{p}=0.9999)$. None of the endoleaks were related to the polar renal artery coverage. Lower limb ischemia occurred respectively in 1 patient (10\%) with polar renal artery covered and 2 patients $(6.1 \%)$ without polar renal artery $(\mathrm{p}=0.5579)$. Major bleeding was observed in 1 patient (10\%) who had polar renal artery covered and 2 patients $(6.1 \%)$ 
without polar renal artery $(\mathrm{p}=0.5579)$. An asymptomatic dissection involving the celiac trunk and the common femoral artery was observed in one patient from the group who did not have polar renal artery.

\section{Discussion}

Our results revealed that the eGFR did not differ at 1 and 7-day post-surgery between patients who had polar renal artery covered and those without polar renal artery. Even though the proportion of renal infarct was significantly higher in patients who had polar renal artery covered, the eGFR did not differ between those who developed renal infarct and those who did not. However, follow-up on a longer period revealed that patients who had polar renal artery coverage tended to have a lower eGFR compared to those without polar renal artery.

Patients who had a polar renal artery covered also tended to have a higher proportion of postoperative decrease of eGFR at the latest follow-up. Taken together our results suggest that the coverage of polar renal artery during FEVAR has a limited impact on early renal function but could affect renal function on longer term. Post-operative renal impairment represents one of the major complications following the treatment of complex aneurysm. A systematic review reported an incidence of early transient renal failure varying between 5 and $25 \%$ following FEVAR, with a pool estimated rate of $14.9 \%$ (16). FEVAR can potentially impact on renal function as well as renal volumes and several events can occur including renal stent occlusion, dissection, fracture, stenosis, kink or renal stent related endoleak (17). As FEVAR can impact on renal function, prevention strategies should be taken to prevent acute kidney injury (18). Several factors can also affect renal function during FEVAR including the operative time, the placement of stents in the renal artery, the variation of blood pressure and the amount of contrast media used during the intervention. 
253 While the consequences on renal function appears as a major challenge during FEVAR, the

254 impact of polar renal artery coverage has been so far poorly investigated. In our cohort, $23.3 \%$

255 of patients had a polar renal artery. This is in accordance with the literature, reporting a

256 prevalence of polar renal artery between 12 and $25 \%$ of the population (7-9). The polar renal

257 artery originated from the abdominal aorta and was oriented to the renal inferior pole in the

258 majority of cases. This represents a classic anatomic variation which has previously been

259 described (7). Several studies addressed the changes of renal function following EVAR and

260 the majority of them did not report any significant difference on post-operative creatinine

261 concentrations and/or eGFR between patients who had polar renal artery covered and those

262 who did not (19-24). Only a few studies reported an early transient impairment of renal

263 function following polar renal artery coverage after $\operatorname{EVAR}(21,25)$. The occurrence of renal

264 infarct following polar renal artery coverage during EVAR has been described in several

265 studies, with ranges varying from $20 \%$ to $84 \%$ of patients $(20-24,26)$. The consequences of

266 the occurrence of renal infarct on renal function in context of polar renal artery coverage

267 during EVAR are heterogeneous. A first study reported a significant decrease of renal

268 function in patients who developed renal infarct compared to those who did not (26), whereas

269 another study did not find any correlation between the extent of kidney infarction and the

270 changes in renal function (21). We found similar results in our cohort involving patients who

271 had FEVAR; $54.5 \%$ of patients who had polar renal artery coverage developed a renal infarct

272 and this was not associated with a significant impairment of early renal function. At last, we

273 did not observe any significant difference on polar artery diameter between patients who

274 developed renal infarct and those who did not. Similar findings were reported by Sadeghi-

275 Azandaryani et al. (26).

276 We found that the 30-day post-operative mortality after FEVAR was $4.7 \%$ in this cohort

277 deemed at high risk for open surgery. This rate is in accordance with other studies which 
reported a 30-day mortality after FEVAR varying between $0.5 \%$ and 9.5\% (27-30). Even if

279 we reported 2 deaths in the group of patients who had polar renal artery covered, the causes of

280 the deaths were not related to the coverage of the polar renal artery.

281 At last, the rate of vascular complications did not differ between patients who had polar renal 282 artery coverage and those who did not. No endoleak related to the vessel covered was

283 reported. These results suggest that polar renal artery thrombosed after coverage and have

284 poor collateralization, which is in accordance with the fact that they represent end-arteries

285 (20). Similar findings were reported by other investigators who did not observe any endoleaks

286 related to accessory renal artery coverage during endovascular aneurysm repair (20, 22-25).

287 However, one study reported the occurrence of type II endoleaks in 3 of 18 patients (17\%)

288 who had polar renal artery coverage (21). Note that in our study, the presence of type II

289 endoleak was detected on early post-operative CT-scan and this could explain why no type II 290 endoleak was observed on this short follow-up period.

291 The consequences of the polar renal coverage on post-operative outcomes are still

292 incompletely understood and there is a lack of consensus on whether the polar renal artery

293 should be preserved or covered. In our cohort, no patient had a revascularization of the polar

294 renal artery. Several authors have proposed the use of chimney grafts as well as commercially

295 or home-made fenestrated endografts to preserve the polar renal artery (31-34). Besides, open

296 and/or hybrid surgery with re-implantation of polar renal arteries remain therapeutic options

297 to preserve renal vascularization. Currently, there is no consensus on the criteria that should

298 be taken into account to preserve or not the polar renal artery. Criteria to choose the most

299 appropriate approach should take in consideration the polar renal artery configuration,

300 patients clinical and anatomic characteristics as well as material available, the experience and 301 the training of the operators (35). 
Several prospects of improvement can be suggested. This was a single-center retrospective

327 Conflicts of interest: none declared vascular function after FEVAR.

\section{Conclusion}

\section{Author contribution}

\section{Acknowledgments: none.} study and given the prevalence of polar renal artery, the number of patients analyzed was small and limited the power of the statistical analysis. The renal function was evaluated on a short post-operative period. It would be worth extending this study to other centers and to prospectively include patients. This would allow us to obtain larger cohorts on a longer follow-up period to evaluate the long-term impact of polar renal artery coverage on renal and

To the best of our knowledge this is the first study to address the impact of polar renal artery coverage after FEVAR for juxta-renal and type IV thoraco-abdominal aneurysms. Patients who had polar renal artery coverage had a higher proportion of post-operative renal infarct. Polar renal artery coverage did not impair early post-operative renal function but can affect renal function on a longer follow-up period. The occurrence of vascular complications at 30day post-surgery did not differ among the groups. Further studies are required to better understand the long-term impact of polar renal artery coverage and clearly define the criteria that should be taken in consideration to choose to cover or preserve it.

All authors confirm they contributed to the intellectual content of this article including conception and design. They revised the manuscript and approved the final version. 
329 Funding Sources: none

330

\section{References:}

332 1. Lederle FA, Freischlag JA, Kyriakides TC, Padberg FT, Jr., Matsumura JS, Kohler

333 TR, et al. Outcomes following endovascular vs open repair of abdominal aortic aneurysm: a

334 randomized trial. JAMA. 2009;302(14):1535-42.

335 2. United Kingdom ETI, Greenhalgh RM, Brown LC, Powell JT, Thompson SG, Epstein

336 D, et al. Endovascular versus open repair of abdominal aortic aneurysm. N Engl J Med.

$3372010 ; 362(20): 1863-71$.

338 3. Graves HL, Jackson BM. The Current State of Fenestrated and Branched Devices for

339 Abdominal Aortic Aneurysm Repair. Semin Intervent Radiol. 2015;32(3):304-10.

340 4. Bungay PM, Burfitt N, Sritharan K, Muir L, Khan SL, De Nunzio MC, et al. Initial 341 experience with a new fenestrated stent graft. J Vasc Surg. 2011;54(6):1832-8.

342 5. Oderich GS, Correa MP, Mendes BC. Technical aspects of repair of juxtarenal 343 abdominal aortic aneurysms using the Zenith fenestrated endovascular stent graft. J Vasc 344 Surg. 2014;59(5):1456-61.

345 6. Greenberg RK, Sternbergh WC, 3rd, Makaroun M, Ohki T, Chuter T, Bharadwaj P, et 346 al. Intermediate results of a United States multicenter trial of fenestrated endograft repair for 347 juxtarenal abdominal aortic aneurysms. J Vasc Surg. 2009;50(4):730-7 e1.

348 7. Panthier F, Lareyre F, Audouin M, Raffort J. Pelvi-ureteric junction obstruction 349 related to crossing vessels: vascular anatomic variations and implication for surgical 350 approaches. Int Urol Nephrol. 2018.

351 8. Ozkan U, Oguzkurt L, Tercan F, Kizilkilic O, Koc Z, Koca N. Renal artery origins 352 and variations: angiographic evaluation of 855 consecutive patients. Diagn Interv Radiol. 
354 9. Urban BA, Ratner LE, Fishman EK. Three-dimensional volume-rendered CT 355 angiography of the renal arteries and veins: normal anatomy, variants, and clinical 356 applications. Radiographics. 2001;21(2):373-86; questionnaire 549-55.

357 10. Crawford ES, Crawford JL, Safi HJ, Coselli JS, Hess KR, Brooks B, et al.

358 Thoracoabdominal aortic aneurysms: preoperative and intraoperative factors determining 359 immediate and long-term results of operations in 605 patients. J Vasc Surg. 1986;3(3):389360404.

361 11. Chaikof EL, Dalman RL, Eskandari MK, Jackson BM, Lee WA, Mansour MA, et al. 362 The Society for Vascular Surgery practice guidelines on the care of patients with an 363 abdominal aortic aneurysm. J Vasc Surg. 2018;67(1):2-77 e2.

364 12. Moll FL, Powell JT, Fraedrich G, Verzini F, Haulon S, Waltham M, et al. 365 Management of abdominal aortic aneurysms clinical practice guidelines of the European 366 society for vascular surgery. Eur J Vasc Endovasc Surg. 2011;41 Suppl 1:S1-S58.

367 13. Fillinger MF, Greenberg RK, McKinsey JF, Chaikof EL, Society for Vascular Surgery 368 Ad Hoc Committee on TRS. Reporting standards for thoracic endovascular aortic repair 369 (TEVAR). J Vasc Surg. 2010;52(4):1022-33, 33 e15.

370 14. Levey AS, Stevens LA, Schmid CH, Zhang YL, Castro AF, 3rd, Feldman HI, et al. A 371 new equation to estimate glomerular filtration rate. Ann Intern Med. 2009;150(9):604-12.

372 15. Bellomo R, Kellum JA, Ronco C. Defining and classifying acute renal failure: from 373 advocacy to consensus and validation of the RIFLE criteria. Intensive Care Med. $374 \quad 2007 ; 33(3): 409-13$.

375 16. Nordon IM, Hinchliffe RJ, Holt PJ, Loftus IM, Thompson MM. Modern treatment of 376 juxtarenal abdominal aortic aneurysms with fenestrated endografting and open repair--a 377 systematic review. Eur J Vasc Endovasc Surg. 2009;38(1):35-41. 
378 17. Martin-Gonzalez T, Pincon C, Maurel B, Hertault A, Sobocinski J, Spear R, et al.

379 Renal Outcomes Following Fenestrated and Branched Endografting. Eur J Vasc Endovasc 380 Surg. 2015;50(4):420-30.

381 18. Saratzis AN, Bath MF, Harrison SC, Sayers RD, Bown MJ. Impact of Fenestrated 382 Endovascular Abdominal Aortic Aneurysm Repair on Renal Function. J Endovasc Ther.

$3832015 ; 22(6): 889-96$.

384 19. Kim B, Donayre CE, Hansen CJ, Aziz I, Walot I, Lippmann M, et al. Endovascular 385 abdominal aortic aneurysm repair using the AneuRx stent graft: impact of excluding 386 accessory renal arteries. Ann Vasc Surg. 2004;18(1):32-7.

387 20. Greenberg JI, Dorsey C, Dalman RL, Lee JT, Harris EJ, Hernandez-Boussard T, et al. 388 Long-term results after accessory renal artery coverage during endovascular aortic aneurysm 389 repair. J Vasc Surg. 2012;56(2):291-6; discussion 6-7.

390 21. Malgor RD, Oderich GS, Vrtiska TJ, Kalra M, Duncan AA, Gloviczki P, et al. A case391 control study of intentional occlusion of accessory renal arteries during endovascular aortic 392 aneurysm repair. J Vasc Surg. 2013;58(6):1467-75.

393 22. Karmacharya J, Parmer SS, Antezana JN, Fairman RM, Woo EY, Velazquez OC, et 394 al. Outcomes of accessory renal artery occlusion during endovascular aneurysm repair. J Vasc 395 Surg. 2006;43(1):8-13.

396 23. Aquino RV, Rhee RY, Muluk SC, Tzeng EY, Carrol NM, Makaroun MS. Exclusion 397 of accessory renal arteries during endovascular repair of abdominal aortic aneurysms. J Vasc 398 Surg. 2001;34(5):878-84.

399 24. Kaplan DB, Kwon CC, Marin ML, Hollier LH. Endovascular repair of abdominal 400 aortic aneurysms in patients with congenital renal vascular anomalies. J Vasc Surg. 401 1999;30(3):407-15.

402 25. Dzieciuchowicz L, Espinosa G, Diaz CV, Lavilla Roya FJ, Lostao JA. Renal function 
403 in patients treated with abdominal aortic stentgraft implantation with an intentional occlusion

404 of accessory renal artery. Ann Vasc Surg. 2012;26(3):299-305.

405 26. Sadeghi-Azandaryani M, Zimmermann H, Korten I, Klose A, Scheiermann P, Treitl

$406 \mathrm{M}$, et al. Altered renal functions in patients with occlusion of an accessory renal artery after

407 endovascular stenting of an infrarenal aneurysm. J Vasc Surg. 2017;65(3):635-42.

408 27. Tsilimparis N, Perez S, Dayama A, Ricotta JJ, 2nd. Endovascular repair with

409 fenestrated-branched stent grafts improves 30-day outcomes for complex aortic aneurysms

410 compared with open repair. Ann Vasc Surg. 2013;27(3):267-73.

411 28. Gupta PK, Brahmbhatt R, Kempe K, Stickley SM, Rohrer MJ. Thirty-day outcomes

412 after fenestrated endovascular repair are superior to open repair of abdominal aortic

413 aneurysms involving visceral vessels. J Vasc Surg. 2017;66(6):1653-8 e1.

414 29. Katsargyris A, Oikonomou K, Kouvelos G, Mufty H, Ritter W, Verhoeven ELG.

415 Comparison of outcomes for double fenestrated endovascular aneurysm repair versus triple or

416 quadruple fenestrated endovascular aneurysm repair in the treatment of complex abdominal

417 aortic aneurysms. J Vasc Surg. 2017;66(1):29-36.

418 30. Raux M, Patel VI, Cochennec F, Mukhopadhyay S, Desgranges P, Cambria RP, et al.

419 A propensity-matched comparison of outcomes for fenestrated endovascular aneurysm repair

420 and open surgical repair of complex abdominal aortic aneurysms. J Vasc Surg.

$421 \quad 2014 ; 60(4): 858-63$; discussion 63-4.

422 31. O'Neill S, Greenberg RK, Haddad F, Resch T, Sereika J, Katz E. A prospective

423 analysis of fenestrated endovascular grafting: intermediate-term outcomes. Eur J Vasc

424 Endovasc Surg. 2006;32(2):115-23.

425 32. Chan YC, Qing KX, Cheng SW. Custom-made fenestrated stent grafts to preserve

426 accessory renal arteries in patients with abdominal aortic aneurysms. Acta Chir Belg.

$427 \quad 2014 ; 114(3): 183-8$. 
429 open and endovascular treatment with fenestrated and chimney endografts for patients with 430 juxtarenal aortic aneurysms. J Vasc Surg. 2012;56(2):285-90.

431 34. Abu Bakr N, Torsello G, Pitoulias GA, Stavroulakis K, Austermann M, Donas KP.

432 Preservation of Clinically Relevant Accessory Renal Arteries in Infrarenal AAA Patients

433 With Adequate Proximal Landing Zones Undergoing EVAR. J Endovasc Ther.

$434 \quad 2016 ; 23(2): 314-20$.

435 35. Lareyre F, Panthier F, Jean-Baptiste E, Hassen-Khodja R, Raffort J. Coverage of

436 Accessory Renal Arteries During Endovascular Aortic Aneurysm Repair: What Are the

437 Consequences and the Implications for Clinical Practice? Angiology. 2018:3319718771249.

438

439

440

441

442

443

444

445

446

447

448

449

450

451

452

453

454 Table 3: Post-operative outcomes of patients who underwent FEVAR

\section{Tables and figure legends:}

Table 1: General characteristics of patients who underwent FEVAR patients without polar renal artery.

Table 2: Procedural and anatomic characteristics of patients who underwent FEVAR patients without polar renal artery.

NA: not applicable

Values are median (interquartile range) or $\mathrm{n}(\%) . \%$ are expressed compared to the number of patients. $\mathrm{P}$ value was calculated comparing patients who had polar renal artery covered and

Values are median (interquartile range) or $\mathrm{n}(\%) . \%$ are expressed compared to the number of patients. $\mathrm{P}$ value was calculated comparing patients who had polar renal artery covered and 
455 Values are median (interquartile range) or $\mathrm{n}(\%) . \%$ are expressed compared to the number of 456 patients. P value was calculated comparing patients who had polar renal artery covered and 457 patients without polar renal artery. For each patient, post-operative decrease of eGFR was 458 estimated as compared to pre-operative values.

459

460

461 Figure 1: Flow chart of the study population 462

463 


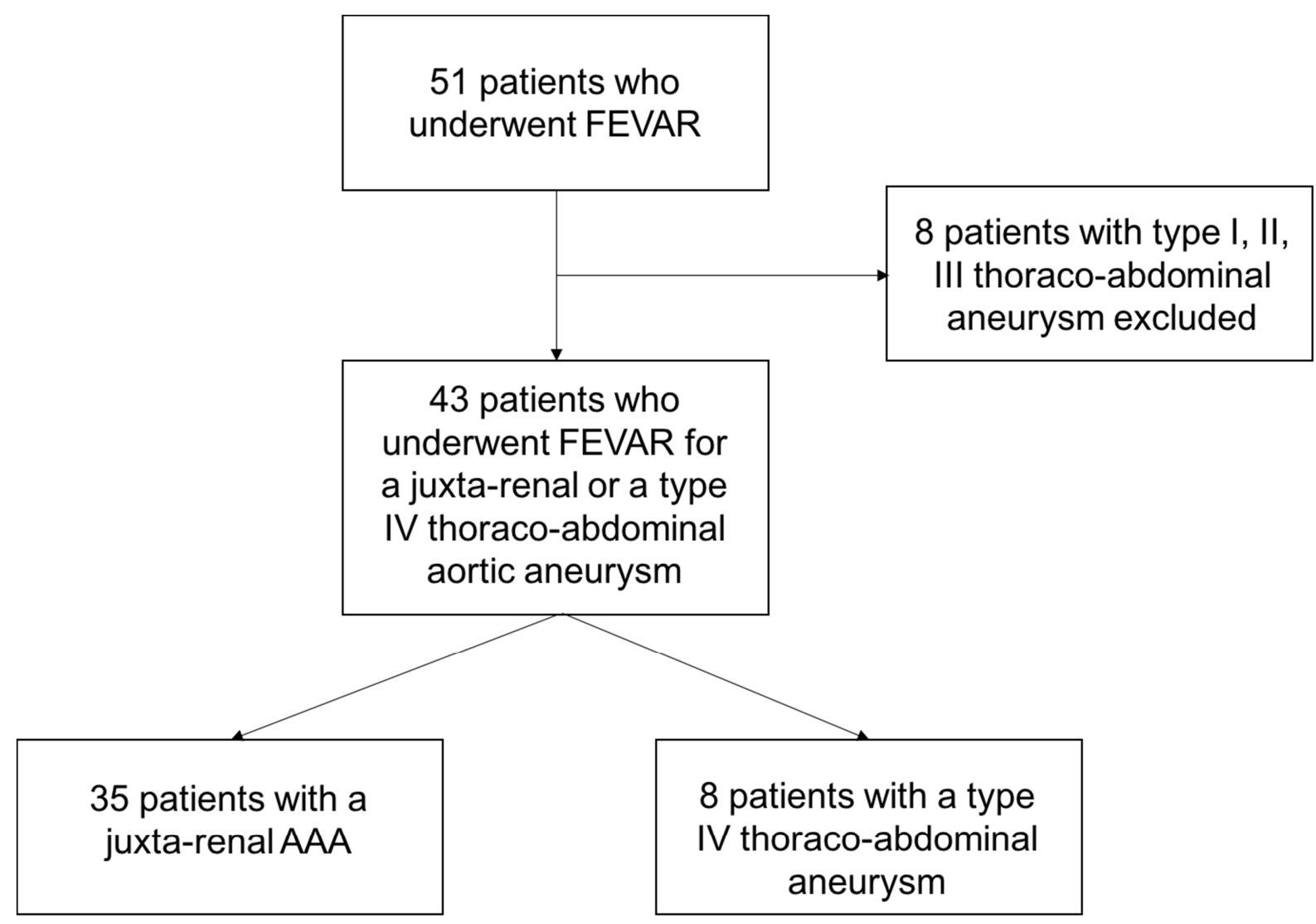

Figure 1: Flow chart of the study population 


\begin{tabular}{|c|c|c|c|c|}
\hline General characteristics & Whole cohort $(n=43)$ & $\begin{array}{l}\text { Patients who had polar } \\
\text { renal artery covered } \\
\qquad(\mathrm{n}=10)\end{array}$ & $\begin{array}{l}\text { Patients without polar } \\
\text { renal artery } \\
(\mathbf{n}=33)\end{array}$ & $P$ value \\
\hline Age & $76(69-83)$ & $73(68-82)$ & $71(71-84)$ & 0.5278 \\
\hline Male sex & $41(95.4 \%)$ & $10(100 \%)$ & $31(93.9 \%)$ & 0.9999 \\
\hline Body mass index $\left(\mathrm{kg} / \mathrm{m}^{2}\right)$ & $23.9(21.3-27.4)$ & $24.4(20.5-27)$ & $23.9(21.3-28.7)$ & 0.8415 \\
\hline Diabetes & $5(11.6 \%)$ & $1(10 \%)$ & $4(12.1 \%)$ & 0.9999 \\
\hline Arterial hypertension & $26(60.5 \%)$ & $5(50 \%)$ & $21(63.6 \%)$ & 0.4809 \\
\hline Dyslipidemia & $14(32.6 \%)$ & $4(40 \%)$ & $10(30.3 \%)$ & 0.7037 \\
\hline Smoking & $34(79.1 \%)$ & $9(90 \%)$ & $25(75.8 \%)$ & 0.6591 \\
\hline Coronary artery disease & $24(55.8 \%)$ & $5(50 \%)$ & $19(57.6 \%)$ & 0.7279 \\
\hline Prior myocardial infarction & $17(39.5 \%)$ & $3(30 \%)$ & $14(42.4 \%)$ & 0.7142 \\
\hline Atrial fibrillation & $6(14 \%)$ & $1(10 \%)$ & $5(15.2 \%)$ & 0.9999 \\
\hline Left ventricle ejection fraction (\%) & $60(50-67.3)$ & $60(50-62.5)$ & $60(50-70)$ & 0.4358 \\
\hline History of stroke & $8(18.6 \%)$ & $3(30 \%)$ & $5(15.2 \%)$ & 0.3617 \\
\hline Chronic obstructive pulmonary disease & $9(20.3 \%)$ & $2(20 \%)$ & $8(24.2 \%)$ & 0.9999 \\
\hline Chronic renal failure & $11(25.6 \%)$ & $1(10 \%)$ & $10(30.3 \%)$ & 0.4086 \\
\hline $\begin{array}{l}\text { American Society of Anesthesiologists } \\
\text { (ASA) score }\end{array}$ & $3(3-3)$ & $3(3-3)$ & $3(3-3)$ & 0.2894 \\
\hline $\begin{array}{l}\text { Pre-operative creatinine concentration } \\
(\mu \mathrm{mol} / \mathrm{L})\end{array}$ & $88(75-108)$ & $91(74.8-109.8)$ & $88(73.5-108.4)$ & 0.9155 \\
\hline $\begin{array}{l}\text { Pre-operative eGFR }\left(\mathrm{mL} / \mathrm{mn} / 1.73 \mathrm{~m}^{2}\right) \\
\text { Pre-operative treatment }\end{array}$ & $71(59.2-85.6)$ & $76(61.5-91.1)$ & $71(56.4-85.4)$ & 0.3865 \\
\hline $\begin{array}{l}\text {. Angiotensin II converting enzyme } \\
\text { inhibitor }\end{array}$ & $16(37.2 \%)$ & $5(50 \%)$ & $11(33.3 \%)$ & 0.4596 \\
\hline . Beta-blocker & $17(39.5 \%)$ & $4(40 \%)$ & $13(39.4 \%)$ & 0.9999 \\
\hline . Angiotensin II receptor blocker & $3(7 \%)$ & $0(0 \%)$ & $3(9.1 \%)$ & 0.9999 \\
\hline Calcium inhibitor & $7(16.3 \%)$ & $1(10 \%)$ & $6(18.2 \%)$ & 0.9999 \\
\hline Diuretics & $11(25.6 \%)$ & $1(10 \%)$ & $10(30.3 \%)$ & 0.4086 \\
\hline . Antiplatelet therapy & $38(88.4 \%)$ & $10(100 \%)$ & $28(84.8 \%)$ & 0.3198 \\
\hline Oral anti-diabetic & $4(9.3 \%)$ & $0(0 \%)$ & $4(12.1 \%)$ & 0.5579 \\
\hline
\end{tabular}




\begin{tabular}{|l|c|c|c|c|}
\hline . Anticoagulant & $6(14 \%)$ & $1(10 \%)$ & $5(15.2 \%)$ & 0.9999 \\
Statin & $26(60.5 \%)$ & $5(50 \%)$ & $21(63.6 \%)$ & 0.4809 \\
\hline
\end{tabular}

Table 1: General characteristics of patients who underwent FEVAR

Values are median (interquartile range) or $\mathrm{n}(\%) . \%$ are expressed compared to the number of patients. $\mathrm{P}$ value was calculated comparing patients who had polar renal artery covered and patients without polar renal artery.

\begin{tabular}{|c|c|c|c|c|}
\hline $\begin{array}{c}\text { Procedural and anatomic } \\
\text { characteristics }\end{array}$ & Whole cohort $(n=43)$ & $\begin{array}{c}\text { Patients who had polar } \\
\text { renal artery covered } \\
(n=10)\end{array}$ & $\begin{array}{l}\text { Patients without polar } \\
\text { renal artery } \\
(\mathbf{n}=33)\end{array}$ & P value \\
\hline Juxta-renal aneurysm & $35(81.4 \%)$ & $8(80 \%)$ & $27(81.8 \%)$ & 0.9999 \\
\hline Type IV thoraco-abdominal aneurysm & $8(18.6 \%)$ & $2(20 \%)$ & $6(18.2 \%)$ & 0.9999 \\
\hline Number of fenestrations & $3(2-4)$ & $3(2-3)$ & $3(2-4)$ & 0.2401 \\
\hline \multicolumn{5}{|l|}{ Type of fenestrated stent graft } \\
\hline .2 fenestrations & $13(30.2 \%)$ & $4(40 \%)$ & $9(27.3 \%)$ & 0.4582 \\
\hline 3 fenestrations & $18(41.9 \%)$ & $5(50 \%)$ & $13(39.4 \%)$ & 0.7174 \\
\hline .4 fenestrations & $12(27.9 \%)$ & $1(10 \%)$ & $11(33.3 \%)$ & 0.2366 \\
\hline \multicolumn{5}{|l|}{ Type of stented vessels } \\
\hline . Right renal artery & $40(93 \%)$ & $10(100 \%)$ & $30(90.9 \%)$ & 0.9999 \\
\hline . Left renal artery & $40(93 \%)$ & $10(100 \%)$ & $30(90.9 \%)$ & 0.9999 \\
\hline . Superior mesenteric artery & $32(74.4 \%)$ & $6(60 \%)$ & $26(78.8 \%)$ & 0.2477 \\
\hline . Celiac trunk & $16(37.2 \%)$ & $1(10 \%)$ & $15(45.5 \%)$ & 0.0635 \\
\hline Operative time (min) & $300(202.5-360)$ & $240(180-420)$ & $300(240-360)$ & 0.4630 \\
\hline Volume of contrast agent $(\mathrm{mL})$ & $132.5(112-187.5)$ & $197(125-285)$ & $135(113-195)$ & 0.2107 \\
\hline Vascular filling volume $(\mathrm{mL})$ & $2000(1500-2500)$ & $2500(2000-2500)$ & $2000(1500-2750)$ & 0.7774 \\
\hline Use of vaso-active drugs during the & $28(65.1 \%)$ & $6(60 \%)$ & $22(66.7 \%)$ & 0.7190 \\
\hline intervention & & & & \\
\hline
\end{tabular}




\begin{tabular}{|c|c|c|c|c|}
\hline $\begin{array}{l}\text { Anatomic characteristics of the polar } \\
\text { renal arteries }\end{array}$ & NA & $3.4(3-4)$ & NA & NA \\
\hline Diameter (mm) & NA & $8(80 \%)$ & NA & NA \\
\hline $\begin{array}{l}\text { Origin } \\
\text {. Aorta }\end{array}$ & NA & $2(20 \%)$ & NA & NA \\
\hline Renal artery & NA & $3(30 \%)$ & NA & NA \\
\hline Localization & NA & $6(60 \%)$ & NA & NA \\
\hline $\begin{array}{l}\text { Superior pole } \\
\text {. Inferior pole } \\
\text {. Hilum }\end{array}$ & NA & $1(10 \%)$ & NA & NA \\
\hline
\end{tabular}

Table 2: Procedural and anatomic characteristics of patients who underwent FEVAR

Values are median (interquartile range) or $\mathrm{n}(\%) . \%$ are expressed compared to the number of patients. $\mathrm{P}$ value was calculated comparing patients who had polar renal artery covered and patients without polar renal artery.

NA: not applicable

\begin{tabular}{|c|c|c|c|c|}
\hline Post-operative outcomes & Whole cohort $(n=43)$ & $\begin{array}{l}\text { Patients who had polar } \\
\text { renal artery covered } \\
(n=10)\end{array}$ & $\begin{array}{l}\text { Patients without polar } \\
\text { renal artery } \\
(\mathbf{n}=33)\end{array}$ & $P$ value \\
\hline Change of medical treatment & $7(16.3 \%)$ & $3(30 \%)$ & $4(12.1 \%)$ & 0.3249 \\
\hline $\begin{array}{l}\text { 1-day post-operative creatinine } \\
\text { concentration }(\mu \mathrm{mol} / \mathrm{L})\end{array}$ & $97(79-118)$ & $93.5(79.8-108)$ & $97(74.5-129)$ & 0.8931 \\
\hline $\begin{array}{l}\text { 1-day post-operative eGFR } \\
\left(\mathrm{mL} / \mathrm{mn} / 1.73 \mathrm{~m}^{2}\right)\end{array}$ & $62.5(48.3-82.1)$ & $69(55.5-83.8)$ & $62(44.2-80.9)$ & 0.5097 \\
\hline $\begin{array}{l}\text { 7-day post-operative creatinine } \\
\text { concentration }(\mu \mathrm{mol} / \mathrm{L})\end{array}$ & $93(78-126)$ & $99.5(78.3-127.5)$ & $91(77.5-126.5)$ & 0.6352 \\
\hline
\end{tabular}




\begin{tabular}{|c|c|c|c|c|}
\hline $\begin{array}{l}\text { 7-day post-operative eGFR } \\
\left(\mathrm{mL} / \mathrm{mn} / 1.73 \mathrm{~m}^{2}\right)\end{array}$ & $71(47.2-81.3)$ & $68(46.7-84.2)$ & $71(46.9-82)$ & 0.9877 \\
\hline $\begin{array}{l}\text { Post-operative creatinine concentration at } \\
\text { the latest follow-up }(\mu \mathrm{mol} / \mathrm{L})\end{array}$ & $110.5(86-175)$ & $159(111.8-253.3)$ & $102.5(81.3-126)$ & 0.0572 \\
\hline $\begin{array}{l}\text { Post-operative eGFR at the latest follow- } \\
\text { up }\left(\mathrm{mL} / \mathrm{mn} / 1.73 \mathrm{~m}^{2}\right)\end{array}$ & $54(34.5-71.8)$ & $38(21.8-56.3)$ & $57(46.5-76)$ & 0.0748 \\
\hline $\begin{array}{l}\text { Post-operative decrease of eGFR (>25\%) } \\
\text { at 1-day }\end{array}$ & $8(18.6 \%)$ & $2(20 \%)$ & $6(18.2 \%)$ & 0.9999 \\
\hline $\begin{array}{l}\text { Post-operative decrease of eGFR (>25\%) } \\
\text { at 7-day }\end{array}$ & $9(21 \%)$ & $2(20 \%)$ & $7(21.2 \%)$ & 0.9999 \\
\hline $\begin{array}{l}\text { Post-operative decrease of eGFR (>25\%) } \\
\text { at the latest follow-up }\end{array}$ & $11(25.6 \%)$ & $4(40 \%)$ & $7(21.2 \%)$ & 0.2477 \\
\hline Kidney renal infarct & $15(34.9 \%)$ & $6(60 \%)$ & $7(21.2 \%)$ & 0.0441 \\
\hline $\begin{array}{l}\text { 30-day post-operative mortality } \\
\text { 30-day post-operative vascular } \\
\text { complications }\end{array}$ & $2(4.7 \%)$ & $2(20 \%)$ & $10(30.3 \%)$ & 0.0498 \\
\hline
\end{tabular}

Table 3: Post-operative outcomes of patients who underwent FEVAR

Values are median (interquartile range) or $\mathrm{n}(\%) . \%$ are expressed compared to the number of patients. $\mathrm{P}$ value was calculated comparing patients who had polar renal artery covered and patients without polar renal artery. For each patient, post-operative decrease of eGFR was estimated as compared to pre-operative values. 